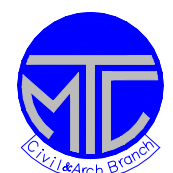

\title{
ICCAE
}

Military Technical College

Kobry Elkobbah, Cairo, Egypt

\author{
6느 International Conference \\ On Civil \& Architecture \\ Engineering
}

\section{A LIMIT STATE DESIGN PROCEDURE FOR WATER-TIGHT R/C SECTIONS \\ ACCORDING TO ECCS 203-2001}

\author{
MOHAMED HUSAIN ${ }^{1}$
}

\begin{abstract}
A limit state design procedure supplemented by design tables and charts was developed for dimensioning reinforced concrete water-tight sections according to the Egyptian code for concrete structures (ECCS 203-2001). The process involves the following two stages: (1) Obtain the section total depth by satisfying the requirements of the cracking limit state. (2) Obtain the required area of steel reinforcement from satisfying the ultimate strength limit state. The procedure omits the calculations required for determining the material under-capacity factor of concrete tensile strength, $\eta$. The $\eta$ factor is a function of the section total depth as well as the state of stresses that the section is sustaining, through the code Eq.(4-69) and the code Table (4-16). The paper introduces a new concept of bending moment about the boundary of the inner core concrete section, $M_{k}$, that proved helpful for sections subject to eccentric tensile or eccentric compressive normal forces.
\end{abstract}

Keywords: water tight structures, design of concrete tanks, limit states, cracking, ultimate strength, modulus of rupture.

\section{Introduction}

In typical reinforced concrete structures the design process is dominated by the ultimate strength limit state, and then the requirements of the serviceability limit state are subsequently satisfied. For water-retaining structures, the opposite is true, where the serviceability limit state or more specifically the cracking limit state moves to the top of the designer concern to dominate the design process. The cross-sectional total depth is to be obtained first, by satisfying the cracking limit state, and then the required area of steel

\footnotetext{
${ }^{1}$ Lecturer of structural Engineering, Zagazig University, Zagazig, Egypt.
} 
is found by satisfying the ultimate limit state. The Egyptian code of concrete structures, ECCS 203-2001 specifies two approaches to satisfy the requirements of the limit state of cracking. The more rigorous approach involves calculations of crack width, and limits the crack width to 0.15 or $0.10 \mathrm{~mm}$ for the category of exposure three and four respectively. The other less rigorous approach is to limit the tensile stresses on the concrete fiber in contact with liquid to $f_{c t r} / \eta$, where $f_{c t r}$ is the modulus of rupture of concrete, and $\eta$ is a material under capacity factor.

This paper employs the later approach to formulate an easy to use, yet accurate, design procedure. This procedure simplifies the necessary calculations for the determination of the factor $\eta$, where a virtual cross-section depth, $t_{v}$, is to be calculated from the code Eq.(4-69). Then from code Table (4-16) the value of $\eta$ is obtained. The value of $\eta$ ranges between 1.0 and 1.70 for $t_{v}$ between 10 and $60 \mathrm{~cm}$ respectively. An upper limit value for the coefficient $\eta$ is set to 1.70 for $t_{v}$ values greater than $60 \mathrm{~cm}$. For the case of axial tension, Eq.(4-69) yields very high value for $t_{v}$, which corresponds to $\eta$ value of 1.70 . On the other hand, for the case of axial compression, Eq.(4-69) yields very low value for $t_{v}$, which corresponds to $\eta$ value of 1.0 .

ECCS code Eq.(4-69) coupled with code Table (4-16) provide high safety factor for sections with large thicknesses, to account for lower concrete quality in thicker sections. Two reasons can be mentioned for the low concrete quality in thicker sections. Firstly, differential volume changes caused by the generated heat of cement hydration are larger in thicker sections, which cause flows and hair cracks in concrete at early age. Secondly, concrete surface curing penetrates large concrete volumes in thinner sections than in thicker ones. Another factor representing structural reliability is introduced to determine the value of $\eta$, that is the fraction of the cross-sectional area that exposed to tensile stresses. The higher the fraction of the section carrying tensile stresses the higher the cracking potential. For sections with total depth less than $60 \mathrm{~cm}$, a value of 1.70 is assigned to $\eta$ for sections totally exposed to tensile stress (the case of axial tensile forces, or small eccentricity tensile forces), while lower values of $\eta$ are given for cases of simple bending and eccentric compression forces. However, the ECCS code ignores this variable for sections of total depth equal or larger than $60 \mathrm{~cm}$.

In the following section the derivation of the design procedure is introduced. Then, design aids for the devised procedure (tables and charts) are presented. Subsequently, some illustrative design examples are given to demonstrate the procedure efficiency. Finally, the paper outlines and conclusions are summarized.

\section{ALLOWABLE TENSILE STRESSES}

The Egyptian code for concrete structures ECCS 203-2001 require water-retaining structures to satisfy the cracking limit state by limiting the tensile stresses on the surface in contact with liquid of concrete elements to the value $f_{c t r} / \eta$, where $f_{\text {ctr }}$ is the modulus of rupture of concrete, and $\eta$ is a material under capacity factor.

\section{The material factor $\eta$}


The values of the code material factor $\eta$ are given in code Table (4-16) versus a variable called the virtual depth, $t_{v}$, can be obtained from code Eq.(4-69) as shown below:

$$
t_{v}=t\left[1+\left(\frac{f_{c t}(N)}{f_{c t}(M)}\right)\right]
$$

Where: $f_{c t}(N)$ is the tensile stresses on section induced by axial tensile force $N$,

$f_{c t}(M)$ is the tensile stresses on section induced by bending moment $M$, and

$t \quad$ is the thickness (total depth) of the considered section.

Tensile stresses can be found as follows:

$$
f_{c t}(N)=N / A_{g} \quad \text { and } \quad f_{c t}(M)=M / Z_{g}
$$

Where, $A_{g}$ and $Z_{g}$ are cross-sectional area, and the modulus of section, respectively.

For rectangular sections of breadth $b$, and thickness $t$ tensile stresses due to axial tension force $N$, and bending moment $M$ are as follows:

$$
\begin{aligned}
f_{c t}(N) & =\frac{N}{b \times t} \\
f_{c t}(M) & =\frac{6 M}{b \times t^{2}}
\end{aligned}
$$

Also Eq.(1) can be reduced to:

$$
t_{v}=t\left[1 \pm\left(\frac{t}{6 \times e}\right)\right]
$$

Where; $\quad e=M / N$

The positive sign is for axial tension, and the negative sign is for compression force. The relation between the factor $\eta$ and $t_{v}$ given in code Table (4-16) can be represented by the graph below: 


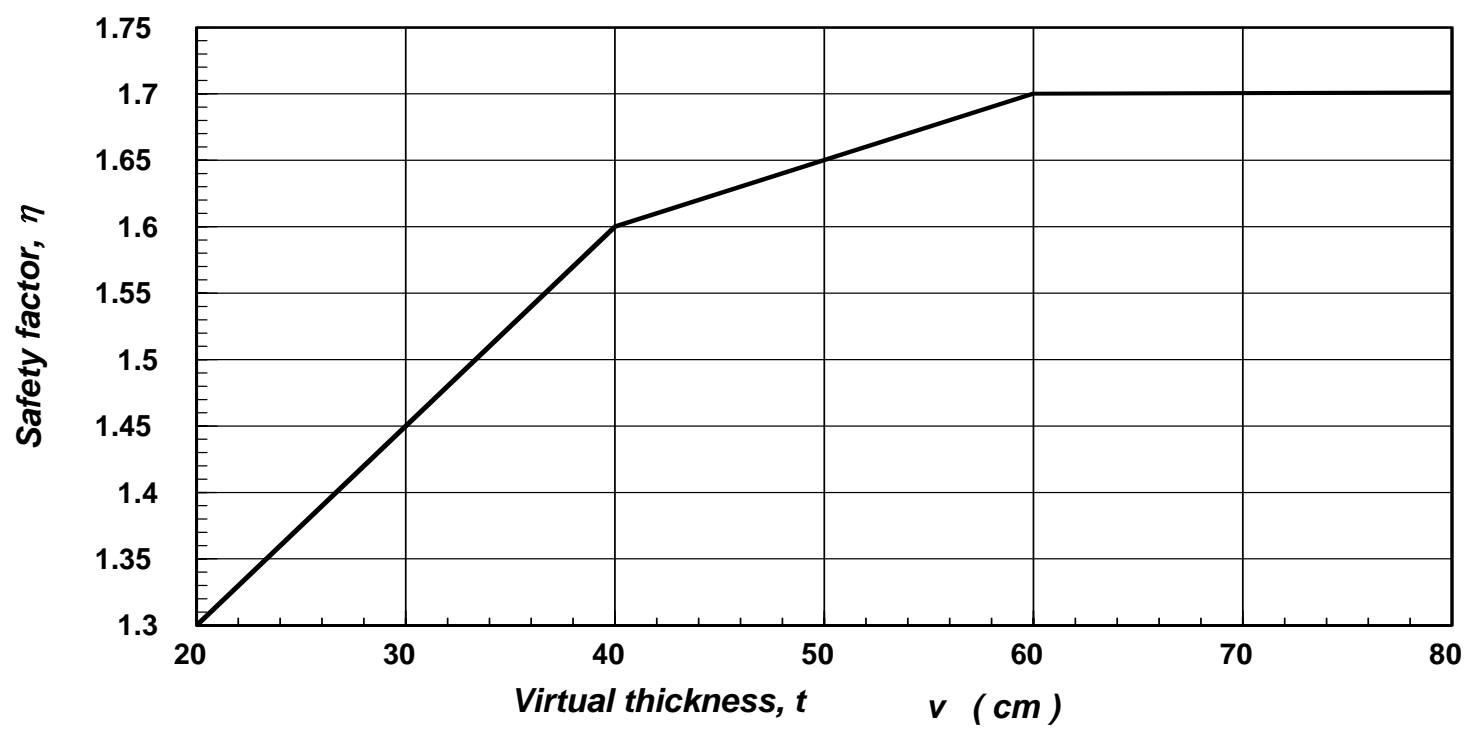

Fig. (1) Virtual thickness $t_{v}-\eta$ relation according to Egyptian code

The previous equation considers the general case in which the section is under the action of axial tension and bending moments simultaneously. Two special cases of this equation are of practical importance:

\section{Case of Axial Tension only:}

The stresses due to moment is zero, i.e. $f_{c t}(M)=0.0$, and plugging it into Eq. (1) yields:

$$
t_{v}=\infty(\geq 60 \mathrm{~cm})
$$

This gives a safety factor against cracking, $\eta=1.7$

\section{Case of Bending Moment only:}

The stress due to axial tension force is zero, i.e. $f_{c t}(N)=0.0$, plugging it into $E q$. (l) yields:

$$
t_{v}=t
$$

And the values of the next table are to be used.

Table (1) Factor $\eta$ for different thicknesses

\begin{tabular}{|c|c|c|c|c|c|}
\hline $\begin{array}{c}\text { Thickness, } t \\
\mathrm{~cm}\end{array}$ & 20 & 30 & 40 & 50 & $\geq 60$ \\
\hline$\eta$ & 1.30 & 1.45 & 1.60 & 1.65 & 1.70 \\
\hline
\end{tabular}


In the general case of loading, the relation between the under capacity factor for concrete tensile strength, $\eta$, and both the section thickness and the axial force eccentricity, $e$, are derived from solving Eq.(4) with the relation drawn in Fig,(1). A computer program in FORTRAN code is formulated to facilitate the calculations of the $\eta$ factor. The values of factor $\eta$ versus the section actual thickness is drawn in Fig. (2) for different values of $e / t$ ratio. In the figure, values of $\eta$ for simple bending $(e / t=\infty)$ are represented by the solid line. Dashed lines in the upper-lift side of figure represent $\eta$ values for sections subject to eccentric tensile force ( $e / t>$ zero ). Dotted-dashed lines in the lower-right side of figure represent $\eta$ values for sections subject to eccentric compressive force $(e / t<$ zero ).

Also the numerical values of the $\eta$ factor are tabulated in Table (2) and Table (3) for the cases of eccentric tensile force and eccentric compressive force respectively.

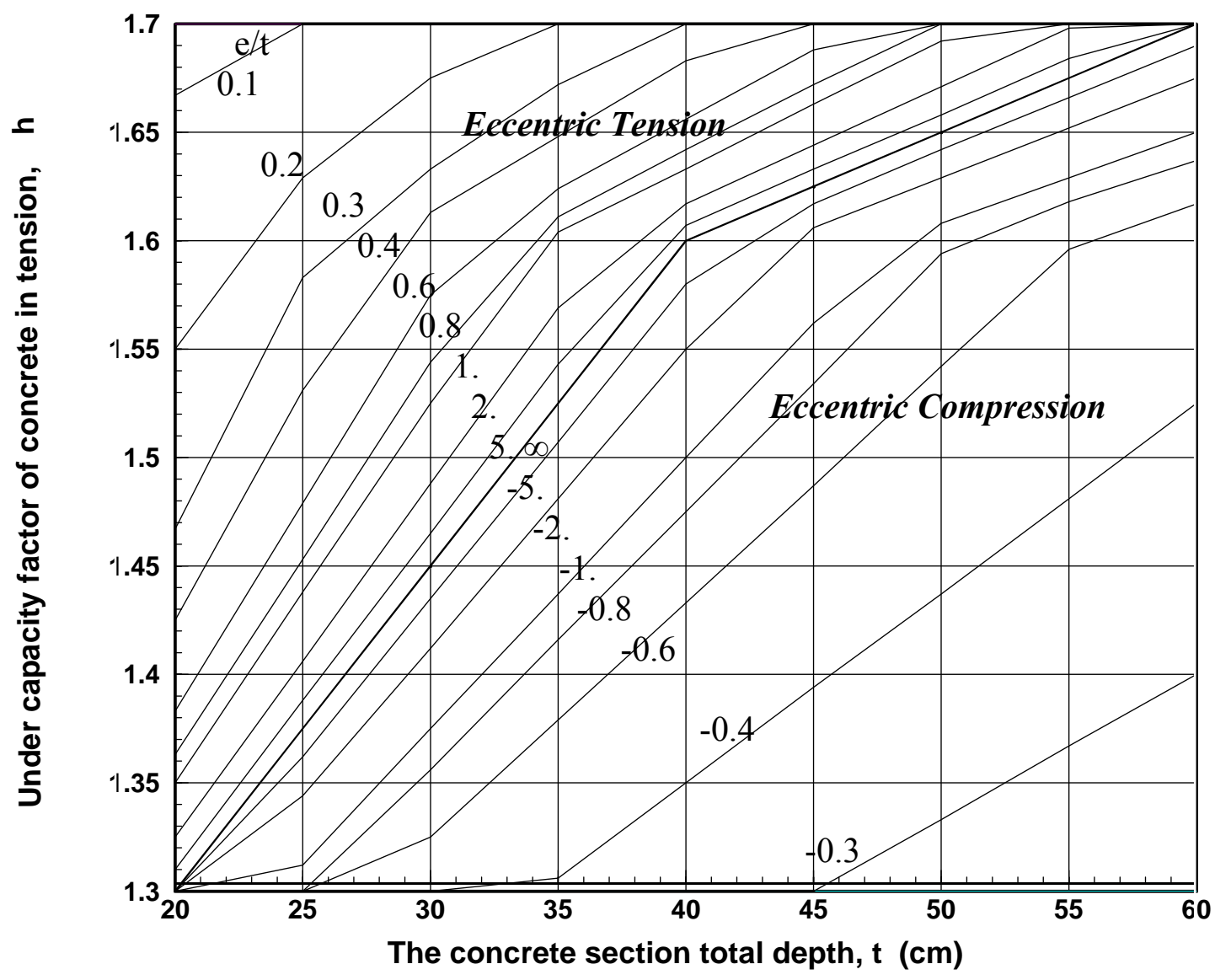


Fig ( 2) Values of under capacity factor for concrete tensile strength

\section{Modulus of rupture $f_{c t r}$}

The modulus of rupture is the extreme tensile stresses at which (concrete) fracture or fail under the effect of bending moments. It is defined by the Egyptian code, ECCS 2032001, by the following equation:

$$
f_{c t r}=1.9 \sqrt{f_{c u}}
$$

Where; $\quad f_{c u}$ is the characteristic concrete cube strength at the age of 28 days.

The units of Eq.(5) are in $\mathrm{kg} / \mathrm{cm}^{2}$. A cap of $30 \mathrm{~kg} / \mathrm{cm}^{2}$ on the value of $f_{c t r}$ is given by the code.

\begin{tabular}{|c|c|c|c|c|c|c|c|c|c|}
\hline & \multicolumn{10}{|c|}{ The total depth of concrete section, $\mathrm{t}(\mathrm{cm})$} \\
\cline { 2 - 11 } $\mathrm{e} / \mathrm{t}$ & $\leq 20.0$ & 25.0 & 30.0 & 35.0 & 40.0 & 45.0 & 50.0 & 55.0 & $\geq 60.0$ \\
\hline$\infty$ & 1.300 & 1.375 & 1.450 & 1.525 & 1.600 & 1.625 & 1.650 & 1.675 & 1.700 \\
\hline 10.0 & 1.305 & 1.381 & 1.457 & 1.534 & 1.603 & 1.629 & 1.654 & 1.680 & 1.700 \\
\hline 5.0 & 1.310 & 1.388 & 1.465 & 1.543 & 1.607 & 1.633 & 1.658 & 1.684 & 1.700 \\
\hline 2.0 & 1.325 & 1.406 & 1.488 & 1.569 & 1.617 & 1.644 & 1.671 & 1.698 & 1.700 \\
\hline 1.0 & 1.350 & 1.438 & 1.525 & 1.604 & 1.633 & 1.663 & 1.692 & 1.700 & 1.700 \\
\hline 0.8 & 1.363 & 1.453 & 1.544 & 1.611 & 1.642 & 1.672 & 1.700 & 1.700 & 1.700 \\
\hline 0.6 & 1.383 & 1.479 & 1.575 & 1.624 & 1.656 & 1.688 & 1.700 & 1.700 & 1.700 \\
\hline 0.4 & 1.425 & 1.531 & 1.613 & 1.648 & 1.683 & 1.700 & 1.700 & 1.700 & 1.700 \\
\hline 0.3 & 1.467 & 1.583 & 1.633 & 1.672 & 1.700 & 1.700 & 1.700 & 1.700 & 1.700 \\
\hline 0.2 & 1.550 & 1.629 & 1.675 & 1.700 & 1.700 & 1.700 & 1.700 & 1.700 & 1.700 \\
\hline 0.1 & 1.667 & 1.700 & 1.700 & 1.700 & 1.700 & 1.700 & 1.700 & 1.700 & 1.700 \\
\hline 0.0 & 1.700 & 1.700 & 1.700 & 1.700 & 1.700 & 1.700 & 1.700 & 1.700 & 1.700 \\
\hline
\end{tabular}

Table (2) Values of the under capacity factor of concrete tensile strength for the cracking limit state ( $\eta)$, for sections subject to eccentric tensile force

\begin{tabular}{|c|c|c|c|c|c|c|c|c|c|}
\hline & \multicolumn{10}{|c|}{ The total depth of concrete section, $\mathrm{t}(\mathrm{cm})$} \\
\cline { 2 - 11 } $\mathrm{e} / \mathrm{t}$ & $\leq 20.0$ & 25.0 & 30.0 & 35.0 & 40.0 & 45.0 & 50.0 & 55.0 & $\geq 60.0$ \\
\hline$\infty$ & 1.300 & 1.375 & 1.450 & 1.525 & 1.600 & 1.625 & 1.650 & 1.675 & 1.700 \\
\hline 10.0 & 1.300 & 1.369 & 1.442 & 1.516 & 1.590 & 1.621 & 1.646 & 1.670 & 1.695 \\
\hline 5.0 & 1.300 & 1.362 & 1.435 & 1.507 & 1.580 & 1.617 & 1.642 & 1.666 & 1.690 \\
\hline
\end{tabular}




\begin{tabular}{|l|l|l|l|l|l|l|l|l|l|}
\hline 2.0 & 1.300 & 1.344 & 1.412 & 1.481 & 1.550 & 1.606 & 1.629 & 1.652 & 1.675 \\
\hline 1.0 & 1.300 & 1.312 & 1.375 & 1.437 & 1.500 & 1.562 & 1.608 & 1.629 & 1.650 \\
\hline 0.8 & 1.300 & 1.300 & 1.356 & 1.416 & 1.475 & 1.534 & 1.594 & 1.618 & 1.637 \\
\hline 0.6 & 1.300 & 1.300 & 1.325 & 1.379 & 1.433 & 1.487 & 1.542 & 1.596 & 1.617 \\
\hline 0.4 & 1.300 & 1.300 & 1.300 & 1.306 & 1.350 & 1.394 & 1.437 & 1.481 & 1.525 \\
\hline 0.3 & 1.300 & 1.300 & 1.300 & 1.300 & 1.300 & 1.300 & 1.333 & 1.367 & 1.400 \\
\hline 0.25 & 1.300 & 1.300 & 1.300 & 1.300 & 1.300 & 1.300 & 1.300 & 1.300 & 1.300 \\
\hline
\end{tabular}

Table (3) Values of the under capacity factor of concrete tensile strength for the cracking limit state ( $\eta$ ), for sections subject to eccentric compressive force

\section{SECTION DIMENSIONING}

The dimensioning process of a concrete section capable of retaining liquids involves the following two stages: (1) Obtain the section total depth by satisfying the requirements of the cracking limit state. (2) Obtain the required area of steel reinforcement from satisfying the ultimate strength limit state. The thickness (total depth) of the section is calculated by equating the extreme tensile stresses on the section by the allowable stresses, $f_{c t r} / \eta$. The next step is to obtain the reinforcement required to provide adequate strength to the section (since concrete tensile resistant can not be assured) from the ultimate limit state. Then, the straining actions used in the cracking limit state is to be multiplied by an ultimate load factor equal 1.4 to obtain the ultimate straining actions. One more code requirement is to reduce the design yield strength of the reinforcing steel by multiplying the yield strength of concrete by a reduction factor, $\beta_{c r}$ less than 1.0 as shown in Table (4):

Table (4) Factor $\beta_{c r}$ for different bar diameters

\begin{tabular}{|c|c|c|c|c|c|}
\hline $\begin{array}{c}\text { Bar } \\
\text { diameter, } \\
(\text { mm) }\end{array}$ & 10 & 12 & 16 & 18 & 22 \\
\hline $\begin{array}{c}\boldsymbol{\beta}_{c r} \\
\text { Smooth } \\
\text { bar (st 37) }\end{array}$ & 1.0 & 1.0 & 0.89 & 0.84 & 0.77 \\
\hline $\begin{array}{c}\beta_{c r} \\
\text { Deformed } \\
\text { bar ( st 52) }\end{array}$ & 0.93 & 0.85 & 0.78 & 0.75 & 0.65 \\
\hline
\end{tabular}

The detailed procedure of the dimensioning process, for all possible combinations of internal actions is introduced next. 


\section{Sections subject to axial tension:}

For the case of axial tensile force, the whole section is subject to uniform tensile stresses. Further, the highest safety factor against cracking, $\eta$, is used $(\eta=1.7)$. The design process will proceed as follows:

(1) Stresses on concrete, $\quad f_{c t}(N)=\frac{N}{b \times t}$

(2) Equate $f_{c t}$ by $\frac{f_{c t r}}{1.7}$ to get the thickness $t$,

$$
t=\frac{N}{b f_{c t r} / 1.7}
$$

(3) Calculate $N_{u}=1.4 \times N$,

Where, 1.4 is the ultimate load factor for water pressure.

(4) Calculate Area of steel, $A_{s}$ :

$$
A_{s}=\frac{N u_{u}}{\beta_{c r} \times\left(f_{y} / \gamma_{s}\right)}
$$

Where, $\beta_{c r}$ is the reduction factor of steel yield stresses.

\section{Sections subject to simple bending moment:}

For the case of bending moment with tensile stresses at liquid side, the section is subject to the highest tensile stresses at its outer fibers in contact with liquid. The safety factor against cracking, $\eta$, is thickness dependent with values as given in Table (1). The design process will proceed as follows:

(1) Assume a starting thickness, $t \approx \sqrt{\frac{M}{3 b}}$

(2) From Table (1) obtain value of $\eta$

(3) Stresses on concrete, $f_{c t}=\frac{6 M}{b \times t^{2}}$

(4) Equate $f_{c t}$ by $\frac{f_{c t r}}{\eta}$ to get the thickness $t$, 


$$
t=\sqrt{\frac{6 \quad M}{b \quad f_{c t r} / \eta}}
$$

(5) Calculate $M_{u}=1.4 \times M$

(6) Calculate Area of steel, $A_{s}$ :

$$
\begin{gathered}
d=t-\operatorname{cover}(4.0 \mathrm{~cm}) \\
C_{1}=d / \sqrt{\frac{M}{f_{c u} \times b}}
\end{gathered}
$$

from $C_{1}-j$ curves find the value of $j$

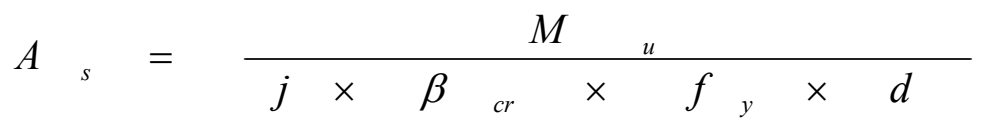

\section{Sections subject to eccentric tensile force:}

In this case both axial tension force and bending moment are simultaneously acting on the concrete section. The highest tensile stresses at its outer fibers in contact with liquid will be the sum of stresses resulting from axial force and moment. The safety factor against cracking, $\eta$, is thickness and eccentricity dependent ( eccentricity, $e=M / N$ ). The design process will go as follows:

(1) Assume a starting thickness, $t \approx 1 \cdot 1 \sqrt{\frac{M}{3 b}}$

(2) Find the eccentricity, $e=M / N$,

$$
\text { then find } t_{v}=t\left[1+\left(\frac{t}{6 \times e}\right)\right]
$$

(3) From Table (1) with $t$ replaced by $t_{v}$, obtain value of $\eta$.

(3) Stresses on concrete, $f_{c t}=\frac{N}{b \times t}+\frac{6 M}{b \times t^{2}}$

(4) Equate $f_{c t}$ by $\frac{f_{c t r}}{\eta}$ to get the required thickness $t$

(5) Calculate $N_{u}=1.4 \times N$ 
and,$e_{s}=e-t / 2+$ cover

(6) For positive values of $\boldsymbol{e}_{\boldsymbol{s}}: \quad M_{u s}=N_{u} \cdot e_{s}$

$$
C_{1}=d / \sqrt{\frac{M}{f_{c u} \times b}}
$$

from $C_{1}-j$ curves find the value of $j$

$$
A_{s}=\frac{M u_{u s}}{j \times \beta_{c r} \times f_{y} \times d}+\frac{N_{u}}{\beta_{c r} \times\left(f_{y} / \gamma_{s}\right)}
$$

For negative values of $e_{s}$ :

$$
\begin{aligned}
& N_{u 2}=N_{u} e_{s} /(d-\text { cover }) \\
& N_{u 1}=N_{u}-N_{u 2} \\
& A_{s 1}=\frac{N_{u 1}}{\beta_{c r} \times\left(f_{y} / \gamma_{s}\right)} \\
& A_{s 2}=\frac{N u_{2}}{\beta_{c r} \times\left(f_{y} / \gamma_{s}\right)}
\end{aligned}
$$

\section{Sections subject to eccentric compression force:}

In this case both axial compression force and bending moment are simultaneously acting on the concrete section, with the highest tensile stresses at its outer fibers in contact with liquid will be the net difference of stresses resulting from bending moment and the axial compressive force. The safety factor against cracking, $\eta$, is thickness and eccentricity dependent ( eccentricity, $e=M / N$ ). The design process will go as follows:

(1) Assume a starting thickness, $t \approx 0.9 \sqrt{\frac{M}{3 b}}$

(2) Find the eccentricity, $e=M / N$,

$$
\text { then find } t_{v}=t\left[1-\left(\frac{t}{6 \times e}\right)\right]
$$


(3) From Table (1) with $t$ replaced by $t_{v}$, or from Fig.(1), obtain value of $\eta$.

(3) Stresses on concrete, $f_{c t}=-\frac{N}{b \times t}+\frac{6 M}{b \times t^{2}}$

(4) Equate $f_{c t}$ by $\frac{f_{c t r}}{\eta}$ to get the required thickness $t$.

(5) Calculate $N_{u}=1.4 \times \mathrm{N}$

and, $e_{s}=e+t / 2$ - cover

(6) For $\boldsymbol{e} / \boldsymbol{t} \geq 0.33$ (big eccentricity): $\quad M_{u s}=N_{u} \cdot e_{s}$

$$
C_{1}=d / \sqrt{\frac{M{ }_{u s}}{f_{c u} \times b}}
$$

from $C_{1}-j$ curves find the value of $j$

$$
A_{s}=\frac{M{ }_{u s}}{j \times \beta_{c r} \times f_{y} \times d}-\frac{N_{u}}{\beta_{c r} \times\left(f_{y} / \gamma_{s}\right)}
$$

For $e / t \leq 0.33$ ( small eccentricity):

The design will be according the interaction diagrams to get, $A_{s}$ and $A_{s}^{\prime}$.

In the case of simple bending Eq. (5) is used to calculate the section overall depth. This equation can be rewritten in the following form:

$$
t=c+\sqrt{\frac{M}{f_{c t r} b}}
$$

Where;

$$
c_{t}=\sqrt{6 \eta}
$$

The form of Eq. (6) is a familiar form to the reinforced concrete designers similar to the equation of the effective depth calculation of the ultimate strength design shown below:

$$
d=c_{1} \sqrt{\frac{M u}{f_{c u} b}}
$$


Therefore the symbol $c_{t}$ is given to the coefficient $\sqrt{6 \eta}$ similar to $c_{t}$.

\section{The concept of $M_{k}$}

When dimensioning sections subject to eccentric force, the equation controlling the section total depth can be written as follows:

$$
\frac{6 M}{b \times t^{2}} \pm \frac{N}{b \times t}=\frac{f_{c t r}}{\eta}
$$

Where the negative sign apply for the eccentric compressive force.

Solving the above equation for the total depth, $t$, will not be appreciated among structural engineers. Therefore, the following manipulations will be made on this equation:

Substitute $M$ in $E q$. (7) by $N . e$ and rewrite the equation:

$$
\left(\frac{6 e}{b \times t^{2}} \pm \frac{1}{b \times t}\right) N=\frac{f_{c t r}}{\eta}
$$

Which can be written as follows:

$$
\frac{6}{b \times t^{2}}\left(e \pm \frac{t}{6}\right) N=\frac{f_{c t r}}{\eta}
$$

Now the expression $(e \pm t / 6)$ can be given the symbol $e_{k}$, that is to mean the force eccentricity measured from the limit of the section core near the compression face (kern, $k= \pm t / 6$ ), as illustrated in Fig (3) below.

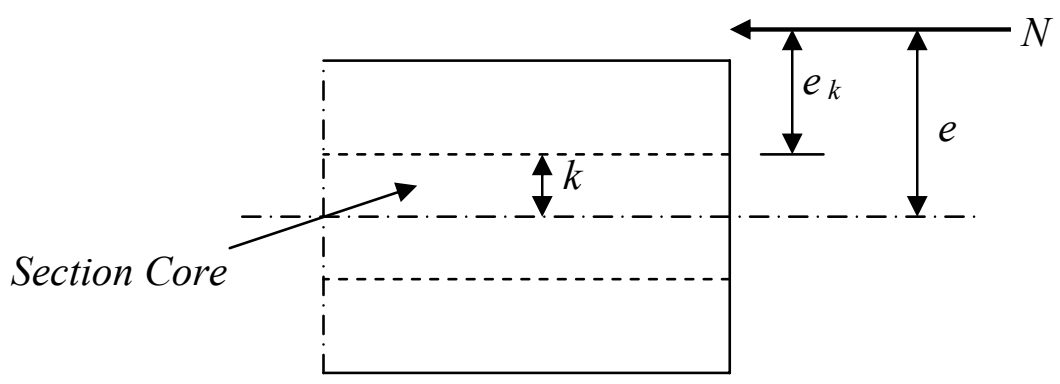

Eccentric compression 


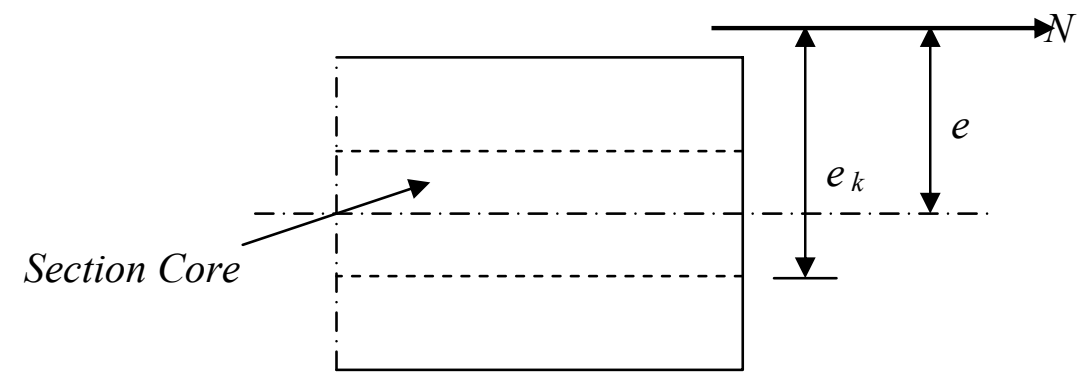

Eccentric tension

Fig. (3) Definition of $e_{k}$

Where in the general case for any section shape:

$$
k=\frac{Z_{g}}{A_{g}}
$$

Now define the moment $M_{k}$ as follows:

$$
M_{k}=N \cdot e_{k}
$$

Where;

$$
e_{k}=e \pm t / 6
$$

Or for general cross-sections:

$$
e_{k}=e+k
$$

Substitute Eq. (8) into Eq.(8),

$$
\frac{6 M{ }_{k}}{b \times t^{2}}=\frac{f_{c t r}}{\eta}
$$

From which the section overall depth can be obtained easily:

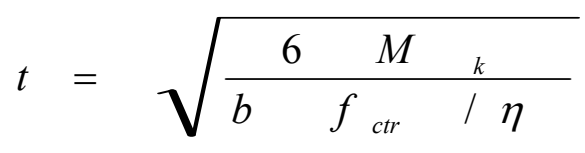

The similarity between $E q$, (10) and Eq. (5) of the simple bending is obvious, and therefore can be rewritten as follows: 


$$
t=c+\sqrt{\frac{M \quad k}{f_{c t r} b}}
$$

Where;

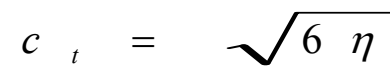

The concept of $M_{k}$, as demonstrated by Eq.(11) helped to turn the process of dimensioning $\mathrm{R} / \mathrm{C}$ sections subject to eccentric normal force into solving one simple equation and determining one coefficient $c{ }_{t}$ similar to the simple bending case.

In conclusion, a simple equation - Eq. (11) - is reached to calculate the total depth of R/C sections to satisfy the requirements of the limit state of cracking, when subject to simple bending or eccentric force with big eccentricity. This equation has a form similar to the equation used to calculate the effective depth of $\mathrm{R} / \mathrm{C}$ sections satisfying the requirements of the ultimate strength limit state for the same internal action conditions. With Eq. (11) and design aids (tables and charts) to determine the value of the coefficient $c_{t}$ the dimensioning process becomes easier and straight forward.

A computer program in FORTRAN code is formulated to facilitate the calculations of the $c_{t}$ coefficient for different combinations of eccentricities and section depths. The values of $c_{t}$ versus the section thickness are drawn in Fig. (4) for different values of e/t ratio. In the figure, simple bending $(e / t=\infty)$ is represented by the solid line. Dashed lines in the upper-lift side of figure represent $\eta$ values for sections subject to eccentric tensile force $(e / t>$ zero $)$. Dotted-dashed lines in the lower-right side of figure represent $\eta$ values for sections subject to eccentric compressive force $(e / t<z e r o)$. Also the numerical values of $c_{t}$ are tabulated in Table (5) and Table (6) for the cases of eccentric tensile force and eccentric compressive force respectively.

\begin{tabular}{|c|c|c|c|c|c|c|c|c|c|}
\hline \multirow{2}{*}{$\mathrm{e} / \mathrm{t}$} & \multicolumn{8}{|c|}{ The total depth of concrete section, $\mathrm{t}(\mathrm{cm})$} \\
\hline & $\leq 20.0$ & 25.0 & 30.0 & 35.0 & 40.0 & 45.0 & 50.0 & 55.0 & $\geq 60.0$ \\
\hline$\infty$ & 2.793 & 2.872 & 2.950 & 3.025 & 3.098 & 3.122 & 3.146 & 3.170 & 3.194 \\
\hline 10.0 & 2.798 & 2.879 & 2.957 & 3.034 & 3.101 & 3.126 & 3.150 & 3.175 & 3.194 \\
\hline 5.0 & 2.804 & 2.886 & 2.965 & 3.043 & 3.105 & 3.130 & 3.154 & 3.179 & 3.194 \\
\hline 2.0 & 2.820 & 2.904 & 2.988 & 3.068 & 3.115 & 3.141 & 3.166 & 3.192 & 3.194 \\
\hline 1.0 & 2.846 & 2.937 & 3.025 & 3.102 & 3.130 & 3.159 & 3.186 & 3.194 & 3.194 \\
\hline 0.8 & 2.860 & 2.953 & 3.044 & 3.109 & 3.139 & 3.167 & 3.194 & 3.194 & 3.194 \\
\hline 0.6 & 2.881 & 2.979 & 3.074 & 3.122 & 3.152 & 3.182 & 3.194 & 3.194 & 3.194 \\
\hline 0.4 & 2.924 & 3.031 & 3.111 & 3.145 & 3.178 & 3.194 & 3.194 & 3.194 & 3.194 \\
\hline 0.3 & 2.967 & 3.082 & 3.130 & 3.167 & 3.194 & 3.194 & 3.194 & 3.194 & 3.194 \\
\hline 0.2 & 3.050 & 3.126 & 3.170 & 3.194 & 3.194 & 3.194 & 3.194 & 3.194 & 3.194 \\
\hline 0.1 & 3.163 & 3.194 & 3.194 & 3.194 & 3.194 & 3.194 & 3.194 & 3.194 & 3.194 \\
\hline 0.0 & 3.194 & 3.194 & 3.194 & 3.194 & 3.194 & 3.194 & 3.194 & 3.194 & 3.194 \\
\hline
\end{tabular}

Table (5) Values of the cracking limit state design coefficient $\left(C_{t}\right)$, for sections subject to eccentric tensile force. 


\begin{tabular}{|c|c|c|c|c|c|c|c|c|c|}
\hline \multirow{2}{*}{$\mathrm{e} / \mathrm{t}$} & \multicolumn{8}{|c|}{ The total depth of concrete section, $\mathrm{t}(\mathrm{cm})$} \\
\cline { 2 - 10 } & $\leq 20.0$ & 25.0 & 30.0 & 35.0 & 40.0 & 45.0 & 50.0 & 55.0 & $\geq 60.0$ \\
\hline$\infty$ & 2.793 & 2.872 & 2.950 & 3.025 & 3.098 & 3.122 & 3.146 & 3.170 & 3.194 \\
\hline 10.0 & 2.793 & 2.866 & 2.941 & 3.016 & 3.089 & 3.119 & 3.143 & 3.165 & 3.189 \\
\hline 5.0 & 2.793 & 2.859 & 2.934 & 3.007 & 3.079 & 3.115 & 3.139 & 3.162 & 3.184 \\
\hline 2.0 & 2.793 & 2.840 & 2.911 & 2.981 & 3.050 & 3.104 & 3.126 & 3.148 & 3.170 \\
\hline 1.0 & 2.793 & 2.806 & 2.872 & 2.936 & 3.000 & 3.061 & 3.106 & 3.126 & 3.146 \\
\hline 0.8 & 2.793 & 2.793 & 2.852 & 2.915 & 2.975 & 3.034 & 3.093 & 3.116 & 3.134 \\
\hline 0.6 & 2.793 & 2.793 & 2.820 & 2.876 & 2.932 & 2.987 & 3.042 & 3.095 & 3.115 \\
\hline 0.4 & 2.793 & 2.793 & 2.793 & 2.799 & 2.846 & 2.892 & 2.936 & 2.981 & 3.025 \\
\hline 0.3 & 2.793 & 2.793 & 2.793 & 2.793 & 2.793 & 2.793 & 2.828 & 2.864 & 2.898 \\
\hline 0.25 & 2.793 & 2.793 & 2.793 & 2.793 & 2.793 & 2.793 & 2.793 & 2.793 & 2.793 \\
\hline
\end{tabular}

Table (6) Values of the cracking limit state design coefficient $\left(C_{t}\right)$, for sections subject to eccentric compressive force.

\section{SUMMARY AND CONCLOSION}

A limit state design procedure supplemented by design tables and charts was developed for dimensioning reinforced concrete water-tight sections according to the Egyptian code for concrete structures (ECCS 203-2001). The process involves the following two stages: (1) Obtain the section total depth by satisfying the requirements of the cracking limit state. (2) Obtain the required area of steel reinforcement from satisfying the ultimate strength limit state. The procedure omits the calculations required for determining the material under-capacity factor of concrete tensile strength, $\eta$. The $\eta$ factor is a function of the section total depth as well as the state of stresses that the section is sustaining, through the code Eq.(4-69) and the code Table (4-16).

The paper introduced a new concept of bending moment about the extremity of the inner core of the concrete section, $M_{k}$, that proved helpful for dimensioning sections subject to eccentric tension or eccentric compression forces. A simple equation - Eq (11)- is reached to calculate the total depth of $\mathrm{R} / \mathrm{C}$ sections to satisfy the requirements of the limit state of cracking, when subject to simple bending or eccentric normal force with big eccentricity. The equation has a familiar form similar to the ultimate strength equation used to calculate the effective depth of $\mathrm{R} / \mathrm{C}$ sections for the same internal action conditions. With $E q$. (11) and the developed design aids (tables and charts), the dimensioning process becomes easier and straightforward.

\section{REFERENCES}

1. ACI 318-98, "Building Code Requirements for Reinforced Concrete;" American Concrete Institute, Redford Station, Detroit, Michigan, USA. 
2. ECCS 203-2001, " The Egyptian Code for Design and Construction of Concrete Structures;" Seventh Edition, 2001, Cairo, Egypt.

3. Meyer, C., " Design of Concrete Structures;" 1996, Printce-Hall, Inc., New Jersey 07458, USA.

4. Reynolds, C. E., "Reinforced Concrete Designer's Handbook;" Tenth Edition, 1999, E \& FN SPON, Taylor and Francis Group, UK.

5. Hilal, M., " Design of Reinforced Concrete Water Tanks;" 1981, J. Marcou \& Co., Abdel Khalek Sarwat, St. Cairo, Egypt. 